\title{
"Online + Offline" Course Teaching Based on Case Teaching Method: A Case Study of Entrepreneurship Education Course
}

\author{
https://doi.org/10.3991/ijet.v15i10.13999 \\ Shuyang Hua ${ }^{(凶)}$, Zhongwei Ren \\ Wuxi Institute of Technology, Wuxi, China \\ $15961834524 @ 139 . \mathrm{com}$
}

\begin{abstract}
Effective entrepreneurship education can not only cultivate students' entrepreneurship awareness and inspire entrepreneurial potential, but also set up an entrepreneurial foundation and form entrepreneurial practice, but the current teaching system doesn't have strong timeliness, due to the high interest of students and lack of rich teaching methods and means by college teachers. Taking "online + offline" entrepreneurship education courses as an example, an "online + offline" teaching mode based on case teaching method was developed in this paper. Based on curriculum theory, the author identified the attractive quality and must-be quality of this course by fully understanding students' needs in the learning process of "online + offline" courses, and designed a questionnaire on the needs for the learning support services of "online + offline" course products, to understand the satisfaction degree of students corresponding to each need. At the same time, combined with the characteristics of the "online + offline" courses, by reference to the evaluation criteria of DEMATEL-ANP, course mentoring, communication, final exam, subtitles and video effect were taken as key indicators, to build an evaluation system to be used in this mode. Finally, the teaching practice proves that this mode can better increase students' learning interest, expand the teaching content of entrepreneurship education course and improve students' satisfaction with this course.
\end{abstract}

Keywords-Case teaching method; "online + offline" courses; entrepreneurship education; evaluation

\section{Introduction}

With the deepening of global social development and economic system reform, the concept of entrepreneurship has gradually been interiorized, and entrepreneurship education has also emerged in response to the advent of knowledge economy and become an inevitable product and urgent demand of the new era. As a concentration place of the training of knowledge groups and high-quality talents, colleges and universities should vigorously carry out entrepreneurship education and constantly deepen the reform of innovation and entrepreneurship education, which can not only accelerate the implementation of innovation-driven development strategy, serve the 
construction of an innovation-type country, but also help deepen the reform of higher education and improve the quality of human resources [1]. However, from the status quo of the teaching of entrepreneurship education course in some colleges and universities, during the implementation of this course, due to inadequate consciousness of schools and insufficient professional abilities of teachers, the effectiveness of entrepreneurship education course teaching in colleges and universities has not been improved, resulting in such problems as the teaching materials are too theoretical, students lack learning interest and teachers lack experience [2]. With the increasing popularity of network technology in the education field, the "online + offline" teaching mode begins to go viral in various fields. The "online + offline" teaching of entrepreneurship education course is faced with new problems. How to truly make "online + offline" teaching effective is a necessity of quality-oriented education reform in the era of big data and informatization.

Taking the "online + offline" teaching mode of entrepreneurship education course as the research object, based on the Kano model of needs, in this paper, a learning support service model applicable to entrepreneurship education course was set up from the perspectives of technical support, resource support, personnel support and emotional support of "online + offline" courses. On this basis, an evaluation system for the "online + offline" entrepreneurship education courses was built and a targeted evaluation indicator system was established from the above perspectives. Guided by these 2 analysis models that were established, during the teaching implementation, according to the theoretical requirements of case teaching method, the application of case method in the teaching of entrepreneurship education course was studied. The purpose of this paper was to explore a more effective teaching mode for web-based courses and truly realize the goal of improving students' quality through entrepreneurship education course.

\section{State of the Art}

The "online + offline" teaching mode means that teachers build an online teaching platform using big data, cloud computing and mobile devices, etc., with the help of computer information technology and modern mobile Internet technology, etc. Teachers upload relevant teaching resources to a corresponding teaching platform and construct interaction and evaluation modules, and students can learn knowledge points on online teaching platforms in a reasonable way according to their own learning and rest schedule, while communicating with their teachers in a timely manner. Under the background of rapid development of big data, the "online + offline" teaching mode has been used in mathematics [3], college physics [4], German [5] and physical education [6], and other courses, and yielded satisfactory teaching results. At the same, domestic and foreign literatures have done a lot of research on case teaching method. Using students in Columbia Business School as samples, Prof. Jaime [7] explored the influence of case teaching method on personal traits of students and teachers. The results of two studies suggested that case teaching was as effective as classroom teaching in terms of learning outcome (i.e. declarative knowledge and situational 
analysis), but had higher student satisfaction. Cakmak [8] combined case teaching method with multiple teaching strategies and methods, and supplemented with teaching materials applicable to the course content and subject. During teaching, they paid attention to using multimedia equipment that attracted students' sensory organs. It was found in an experiment that case teaching method can help students achieve a positive learning effect. The team of Mcwhirter et al. [9] built an engineering teaching module based on case teaching method, and combined evaluation system with the science of behavioral decision-making. Three complete modules can be used by users to modify, use and review. This method was used in a case study on electric field design. The results before and after the investigation showed that the students' learning ability had been significantly improved ( $\mathrm{p}<0.05)$, and case teaching method can satisfy a variety of teaching demands of engineering education. Among them, many literatures have done a lot of research on case teaching method and case teaching method of entrepreneurship education course. Chen [10] constructed a "trinity" entrepreneurship education model, i.e., universities, enterprises and society, to offer professional entrepreneurship services for college entrepreneurs and solve process problems encountered by entrepreneurs in a targeted way. The results showed that this kind of practical learning can improve students' independent entrepreneurial ability. $\mathrm{Ju}$ [11], taking agriculture majors as an example, believed that entrepreneurship education needed to build a profession-driven, project-driven, platform-driven and mechanism-driven education mode, according to the training needs of entrepreneurial talents in the field of agriculture. This mode can push the reform of entrepreneurship education in an all-round way, and improve students' entrepreneurship level. Wei et al. [12] proposed that the entrepreneurship education and professional courses in colleges were not fused in terms of teachers. Most professional teachers lack experience in entrepreneurship, and some even lack entrepreneurship awareness and entrepreneurial ability. On the other hand, teachers undertaking entrepreneurship education are mostly ignorant of students' professional knowledge, thereby reducing students' learning interest and leading to such undesirable phenomena as learning burnout. While $\mathrm{Gu}$ [13] argued that case teaching method was problematic in that the allocation of teaching time was unreasonable, the case application was unscientific and the application skills of teachers were poor. To sum up, the above contents provide a significant reference for the reform of online teaching mode of entrepreneurship education course and serve as the theoretical foundation of this paper.

\section{Specific Forms of "Online + Offline" Teaching of Entrepreneurship Education Course Based on Case Teaching Method}

\subsection{Case teaching method based on the needs for the learning support services of "Online + Offline" courses}

In colleges and universities in China, more and more students are inclined to adopt online learning mode, and how to offer learning support services under this mode has 
also become a primary issue to be solved urgently during the learning of "online + offline" courses. By referring to the Kano model of needs [14], the author examined the quality characteristics of "online + offline" course products. The satisfaction degree of those in need in the process of learning was investigated and the attributes of "online + offline" courses can be represented as attractive quality and must-be quality. Attractive quality meant that the education product can offer this attribute and students reported a high satisfaction. However, if this attribute was not offered, students wouldn't feel disappointed or sad, but interpreted it as "acceptable", and their satisfaction with the products wouldn't be affected. Even if the value of this attribute was further optimized and improved, the students' satisfaction wouldn't be significantly enhanced accordingly. The schematic is shown in Fig. 1 below.

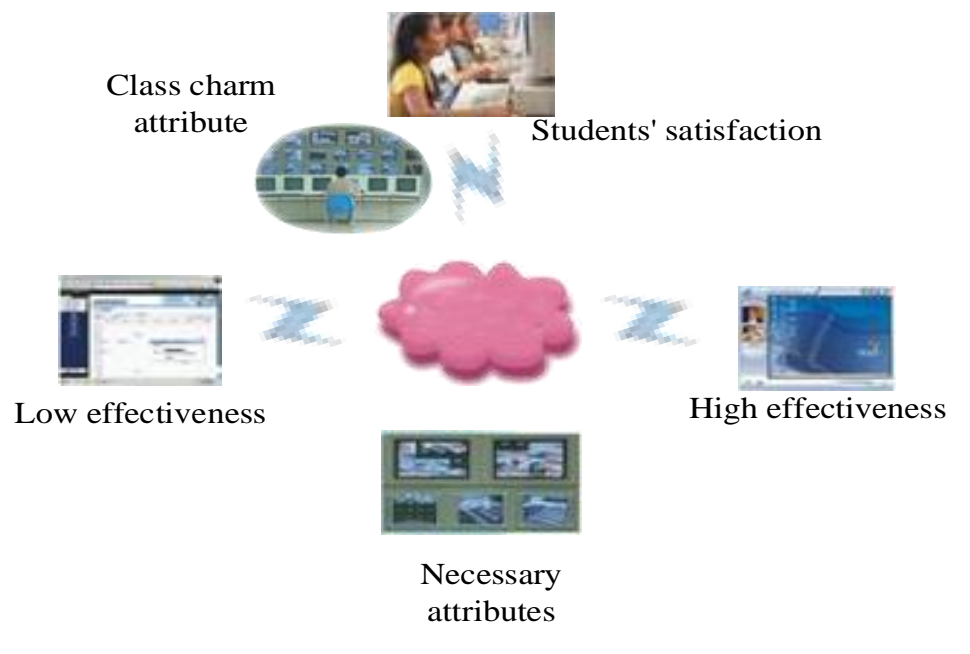

Fig. 1. Two-dimensional Quality Model of the "Online + Offline" Courses

In this paper, taking the entrepreneurship education course of colleges and universities in China as the research object, the author identified the attractive quality and must-be quality of this course by fully understanding students' needs in the learning process of "online + offline" courses and designed a questionnaire on the needs for the learning support services of "online + offline" course products, to gain a deep insight into the satisfaction degree of students corresponding to each need. For each need $\mathrm{i}$, forward question and reverse question were designed from two aspects, that is, whether the students were satisfied, the structure was drawn from a 5-point Likert scale, which decreased from "I like it" to "I don't like it" progressively. It was applied to the "questionnaire on learners' needs for the learning support services of "online + offline" courses". The questionnaire was designed as shown in the table 1: 
Paper — "Online + Offline" Course Teaching Based on Case Teaching Method: A Case Study...

Table 1. The Designed Content of the Questionnaire on Learners' Needs for The Learning Support Services of "Online + Offline" Courses

\begin{tabular}{|c|c|c|}
\hline Analytical Angle & Content & Learners' Sensory Satisfaction \\
\hline \multirow{5}{*}{ Forward Analysis } & \multirow{5}{*}{ Learner's feeling about having the attribute $\mathrm{i}$} & I appreciate it \\
\hline & & It is a must \\
\hline & & It is nice to have \\
\hline & & I can bear it \\
\hline & & I don't like it \\
\hline \multirow{5}{*}{ Reverse Analysis } & \multirow{5}{*}{ Learner's feeling about not having the attribute $\mathrm{i}$} & I appreciate it \\
\hline & & It is a must \\
\hline & & It is nice to have \\
\hline & & I can bear it \\
\hline & & I don't like it \\
\hline
\end{tabular}

According to the design idea of this questionnaire, questionnaires were distributed to probe into the satisfaction degree of learners with the attributes of this course. According to the summarized results of questionnaires, the data were analyzed, and the value of need for each attribute of the "online + offline" courses was evaluated. The method is shown in Tab. 2 below, where " $\mathrm{N}$ " stood for the need of must-be quality, "C" for the need of attractive quality, " $H$ " for the need of one-dimensional (expected) quality, "R" for reverse need, " $S$ " for undifferentiated need, and "Q" for paradox in the respondent's answer, which was labeled as "problematic answer".

Table 2. Evaluation and Analysis of the Questionnaire on Learners' Needs for the Learning Support Services of "Online + Offline" Courses

\begin{tabular}{|l|c|c|c|c|c|}
\hline \multirow{2}{*}{ Forward Analysis } & \multicolumn{5}{|c|}{ Reverse Analysis } \\
\cline { 2 - 6 } & I appreciate it & It is a must & It is nice to have & I can bear it & I don't like it \\
\hline I appreciate it & $\mathrm{Q}$ & $\mathrm{C}$ & $\mathrm{C}$ & $\mathrm{C}$ & $\mathrm{H}$ \\
\hline It is a must & $\mathrm{R}$ & $\mathrm{S}$ & $\mathrm{S}$ & $\mathrm{S}$ & $\mathrm{N}$ \\
\hline It is nice to have & $\mathrm{R}$ & $\mathrm{S}$ & $\mathrm{S}$ & $\mathrm{S}$ & $\mathrm{N}$ \\
\hline I can bear it & $\mathrm{R}$ & $\mathrm{S}$ & $\mathrm{S}$ & $\mathrm{S}$ & $\mathrm{N}$ \\
\hline I don't like it & $\mathrm{R}$ & $\mathrm{R}$ & $\mathrm{R}$ & $\mathrm{R}$ & $\mathrm{Q}$ \\
\hline
\end{tabular}

In the end, the frequency of each item in Tab. 2 was summarized and analyzed using "maximum frequency method", and a model for the needs for the learning support services of this course was obtained, as shown in Fig. 2. This model showed 6 primary indictors and 20 secondary indictors used in the evaluation of the "online + offline" courses. 


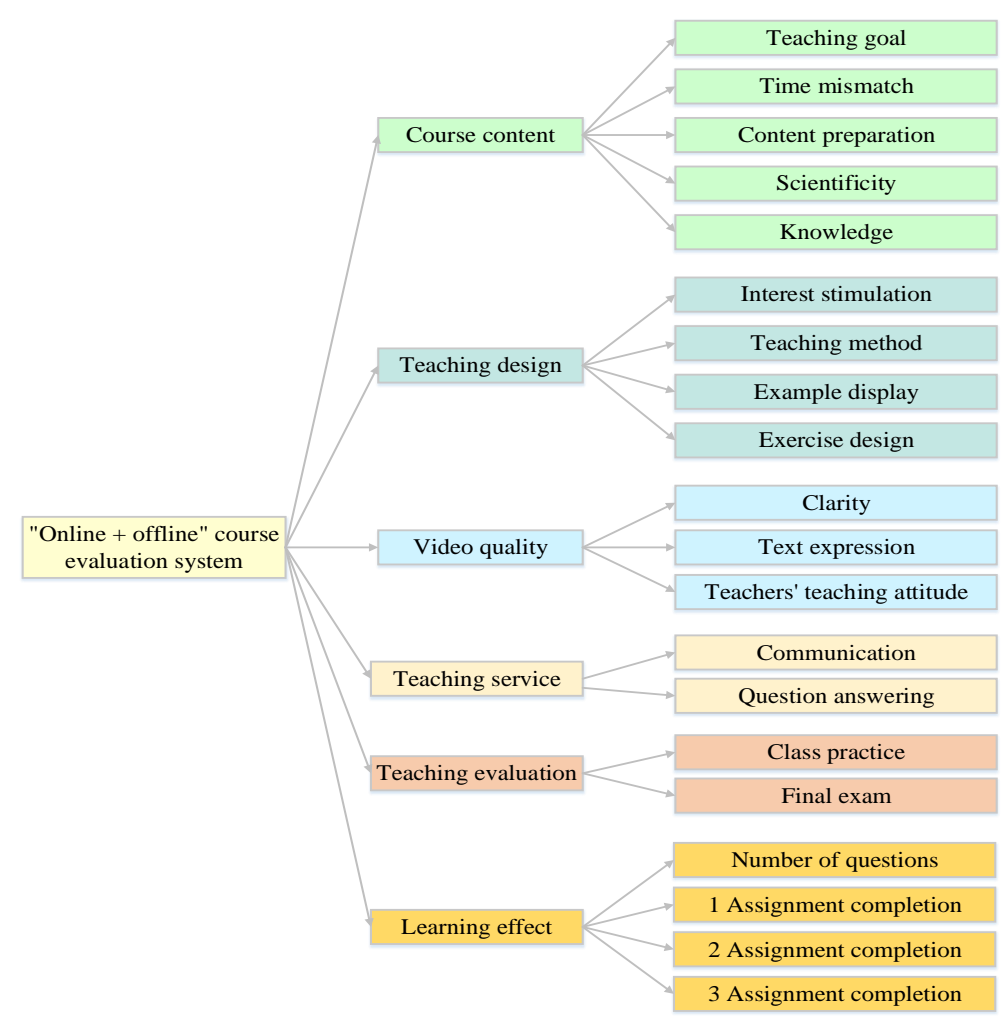

Fig. 2. The Evaluation Indicator System for "Online + Offline" Courses

It can be seen from Fig. 2 that the evaluation system for the learning support services of this course involved 6 indicators, and 6 dimensions were analyzed specifically: (1) course content (A): the course content mainly included teaching objective, consistency between content and objective, content arrangement, scientificity and knowledge quantity; (2) teaching design (B): the teaching design mainly included the interest stimulation, teaching mode, example demonstration and exercise design; (3) video quality $(\mathrm{C})$ : the video quality mainly included the definition of videos, correctness of subtitles and teacher's sense of lens; (4) teaching services (D): the teaching services mainly included course mentoring and communication; (5) teaching assessment (E): the teaching assessment mainly included classroom exercises and final exam; (6) learning effect (F): the learning effect mainly included the rationality of frequency of questioning, the participation rate of homework, the completion rate of homework and the passing rate of exam. 


\subsection{Entrepreneurship education classes integrating the new case teaching method}

Entrepreneurship education course is boring, and the concepts and theories in it are obscure and hard to understand. In actual implementation, the theory is easily divorced from practice, and leads to low interest of students and low teaching quality [10]. Therefore, to deepen students' understanding of professional knowledge, make unintelligible and boring theories close to life and mobilize students' learning interest and initiative, teachers needed to bridge the concepts and principles of theory course and entrepreneurship reality, to make theory and practice interconnected, open up new ideas for students and arouse their learning interest. This bridge is precisely case teaching method.

Case teaching method is a case-based teaching method. The so-called cases, in essence, require teachers to offer a kind of situation where teacher plays the role of designers and motivators and encourage students, while learners take an active part in discussion. It is obviously different from the "teaching and imparting" state in the traditional teaching method, and teachers are more like facilitators. The subject of case teaching method is students, and it is generally used in the cultivation of advanced intellectual skills, for example, the development of the abilities to analyze, synthesize and evaluate [11].

In order to apply case teaching method to entrepreneurship education course, we need to adopt proper and moderate cases and shorten the distance between students and boring theories. Only in this way can teaching develop in a progressive way from imparting knowledge to cultivating abilities and innovative thinking. However, in reality, case teaching method has posed a dilemma to the traditional teaching and education concepts, and there are no specific solutions, so we need carry out a deep study according to the characteristics of the course content that we teach.

\subsection{Establishing evaluation for the teaching effect of entrepreneurship education cases based on DEMATEL-ANP}

The evaluation indicator system for the "online + offline" courses was analyzed, which covered 6 aspects: course content, teaching design, video quality, teaching services, teaching assessment and learning effect. However, the correlation degree between each evaluation indicator was different, and some correlation degree was not so obvious. Hence, to reduce unnecessary correlation analysis between the evaluation indicators, the author conducted an in-depth analysis on the mutual influence between the 6 indicator systems above using DEMATEL [12], to gain an insight into the network structure among primary indicators.

An initial influence matrix was set up. The values of $0,1,2,3$ and 4 were used to judge the influence relationship between each indicator set, and an initial average influence matrix for indicator set $A_{\mathrm{i}}$ was constructed. 


$$
A_{\mathrm{i}}=\left[\begin{array}{cccc}
a_{11} & a_{12} & \ldots & a_{1 n} \\
a_{12} & a_{22} & \ldots & a_{2 n} \\
\vdots & \vdots & \vdots & \vdots \\
a_{n 1} & a_{n 1} & \ldots & a_{n n}
\end{array}\right]
$$

$A_{\mathrm{i}}$ was standardized to obtain a direct influence matrix, $B=\mathrm{S}{ }_{\mathrm{i}}$, among which

$$
S=\min \left(\frac{1}{\max _{1 \leq i \leq n} \sum_{i=1}^{n} a_{i j}}, \frac{1}{\max _{1 \leq j \leq n} \sum_{j=1}^{n} a_{i j}}\right)
$$

Where $i, j=1,2, \ldots n$.

According to the influence matrix calculated by the above formula, the comprehensive effect of each factor was considered and a comprehensive influence matrix was obtained.

$$
T=X(1-X)^{-1}
$$

The child element of this indicator was $t_{\mathrm{ij}}$. The resulting ${ }^{t_{\mathrm{ij}}}$ was analyzed, and a threshold $\mathrm{P}$ was set according to the experts' opinions. If $t_{\mathrm{ij}} \geq \mathrm{P}$, then the correlation degree was considered to be high, and corresponding indicators were linked. In this way, the network structure diagram among primary indicators (indicator set) can be obtained. The value of $\mathrm{P}$ may affect the complexity of the network structure diagram, so an appropriate $\mathrm{P}$ should be determined according to the experts' opinions.

The influence relationship among secondary indicators was analyzed by analytic hierarchy process (ANP), and the weights of the evaluation indicators of the course were calculated. The method was the same as above.

According to the above analysis method, the evaluation indicators of the "online + offline" entrepreneurship education courses were analyzed. 3 "online + offline" course experts were invited to form an expert committee, evaluate the course and tally the score of each indicator. According to the above method, an analysis was performed to obtain a comprehensive influence matrix. The values of the matrix elements are shown in Tab. 3 below. 
Paper — "Online + Offline" Course Teaching Based on Case Teaching Method: A Case Study...

Table 3. The Values of the Elements of the Comprehensive Influence Matrix ()

\begin{tabular}{|l|c|c|c|c|c|c|}
\hline & A & B & C & D & E & F \\
\hline A & 0.530 & 0.548 & 0.833 & 0.684 & 0.515 & 0.775 \\
\hline B & 0.716 & 0.513 & 0.935 & 0.865 & 0.742 & 0.744 \\
\hline C & 0.720 & 0.475 & 0.485 & 0.659 & 0.510 & 0.612 \\
\hline D & 0.505 & 0.682 & 0.732 & 0.612 & 0.452 & 0.630 \\
\hline E & 0.871 & 0.653 & 0.692 & 0.545 & 0.3923 & 0.846 \\
\hline F & 0.599 & 0.593 & 0.846 & 0.632 & 0.589 & 0.532 \\
\hline
\end{tabular}

A simplified network structure diagram among primary indicators was obtained by AHP, as shown in Fig. 3, where the threshold $\mathrm{P}$ was adjusted several times according to the experts' opinions and finally defined as $\mathrm{P}=0.55$.

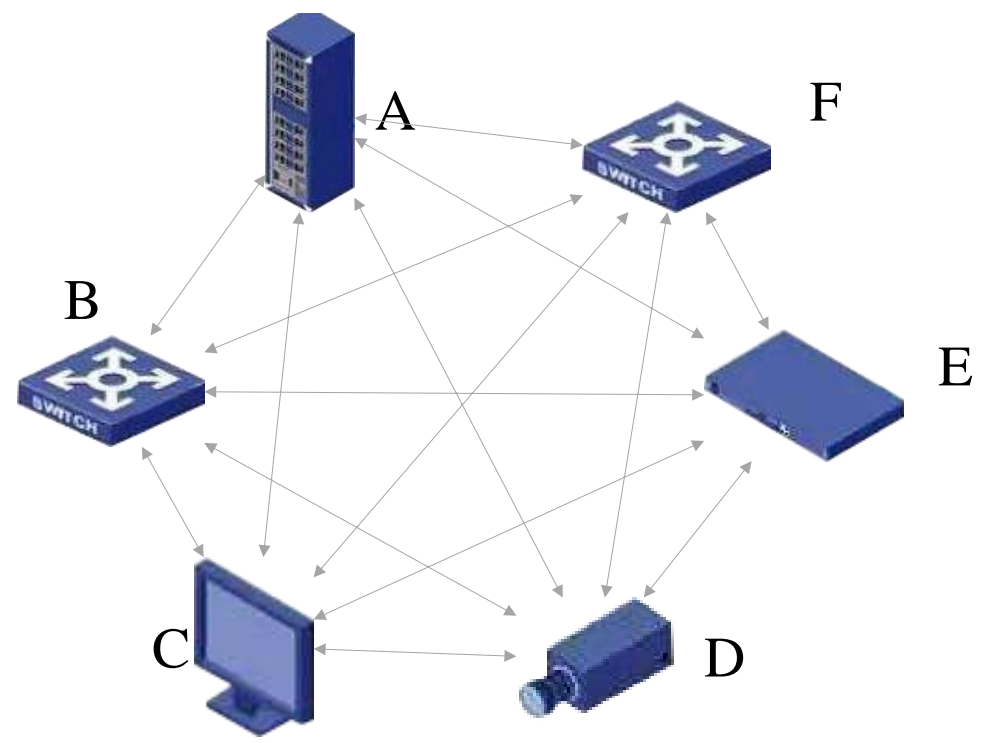

Fig. 3. Network teaching mode oriented to teaching resource self-organization

It can be seen that the correlation degree among primary indicators in each model was high, so a correlation analysis was also made on the secondary indicators, and the global weight of the evaluation indicators of the "online + offline" courses was obtained, as shown in Tab. 4. 
Paper — "Online + Offline" Course Teaching Based on Case Teaching Method: A Case Study...

Table 4. The Global Weight of the Evaluation Indicators of "Online + Offline" Courses

\begin{tabular}{|l|c|c|l|c|c|}
\hline \multicolumn{1}{|c|}{ Indicator Name } & $\begin{array}{c}\text { Weight in } \\
\text { First-class } \\
\text { Indicators }\end{array}$ & $\begin{array}{c}\text { Global } \\
\text { Weight }\end{array}$ & \multicolumn{1}{|c|}{ Indicator Name } & $\begin{array}{c}\text { Weight in } \\
\text { First-class } \\
\text { Indicators }\end{array}$ & $\begin{array}{c}\text { Global } \\
\text { Weight }\end{array}$ \\
\hline Course Mentoring & 0.553 & 0.127 & Proportion of Homework & 0.213 & 0.044 \\
\hline Teaching Objective & 0.294 & 0.042 & Teacher's Sense of Lens & 0.356 & 0.075 \\
\hline Final Exam & 0.561 & 0.068 & Courseware Arrangement & 0.216 & 0.031 \\
\hline Interest stimulation & 0.245 & 0.021 & Frequency of questioning & 0.293 & 0.052 \\
\hline Video Effect & 0.293 & 0.054 & Succinctness of Content & 0.152 & 0.020 \\
\hline Scientificity of Content & 0.146 & 0.020 & Passing Rate of Exam & 0.250 & 0.051 \\
\hline Completion Rate of Homework & 0.240 & 0.043 & Example demonstration & 0.123 & 0.012 \\
\hline Communication & 0.445 & 0.103 & Knowledge quantity & 0.181 & 0.025 \\
\hline Teaching Mode & 0.381 & 0.040 & Classroom Exercise & 0.433 & 0.052 \\
\hline Subtitles & 0.331 & 0.065 & Exercises & 0.204 & 0.020 \\
\hline
\end{tabular}

According to Tab. 4, the weight of each indicator of the "online + offline" entrepreneurship education courses was obtained, among which close attention should be paid to several indicators, such as course mentoring, communication, final exam, subtitles and video effect. These were important indicators for evaluating the effect of course implementation, and also important factors that affected the effect of course implementation.

In view of the content of the entrepreneurship education course, in this paper, new entrepreneurship education classes based on case teaching method were designed. The course content designed is shown in Fig. 4 below. Before class, teachers needed to select cases, combined with the content of the chapter to be taught, and around students' learning interest while explaining the cases. In the meantime, teachers needed to clearly define students' learning objectives, identify several knowledge points to be understood or considered, and analyzed important points, difficult points and learning methods in a targeted manner, introduce ways to organize learning resources, lead students to inquire independently by imitating the cases, analyze the conclusions of cases and summarize the results of inquiry, and teachers needed to expand these cases subsequently, to match students' knowledge expansion after inquiry, and produce new cases to lead students to take a step further, and participate in the follow-up evaluation of teaching effect. 


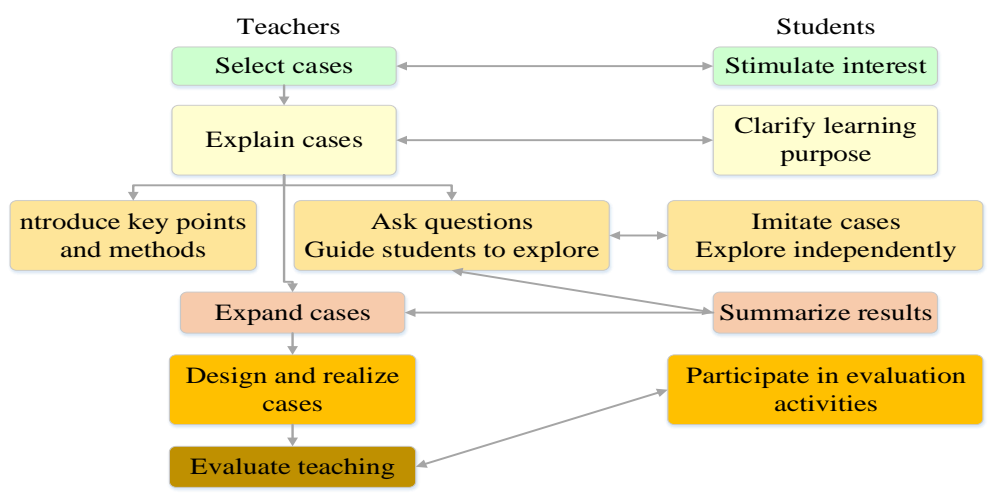

Fig. 4. Establishing a Case Teaching Method for "Online + Offline" entrepreneurship education Courses

\section{$4 \quad$ Teaching Example and Effect}

\subsection{Teaching example}

According to the above-mentioned application mode of case teaching method in "online + offline" courses, in this paper, an all-round reform was carried out on the course. Considering that the idea of quality-oriented education must fully respect students' cognition rules, in the process of implementation, an "online + offline" teaching mode dominated by teachers, oriented to students and based on media technology was taken, a student case teaching mode was created and the teaching procedures of "asking questions, students learning by themselves- teaching cases, deepening knowledge architecture -discussing case, feedback and correction" were established, whose connotations can be expressed as: in the context where teachers guided and students learned independently, students established a student-oriented inquiry process, by designing cases, deepening knowledge architecture, and carrying out a series of cooperation and discussions, and their learning interest was aroused through the medium of questions. The operating procedures are shown in Fig. 5. 


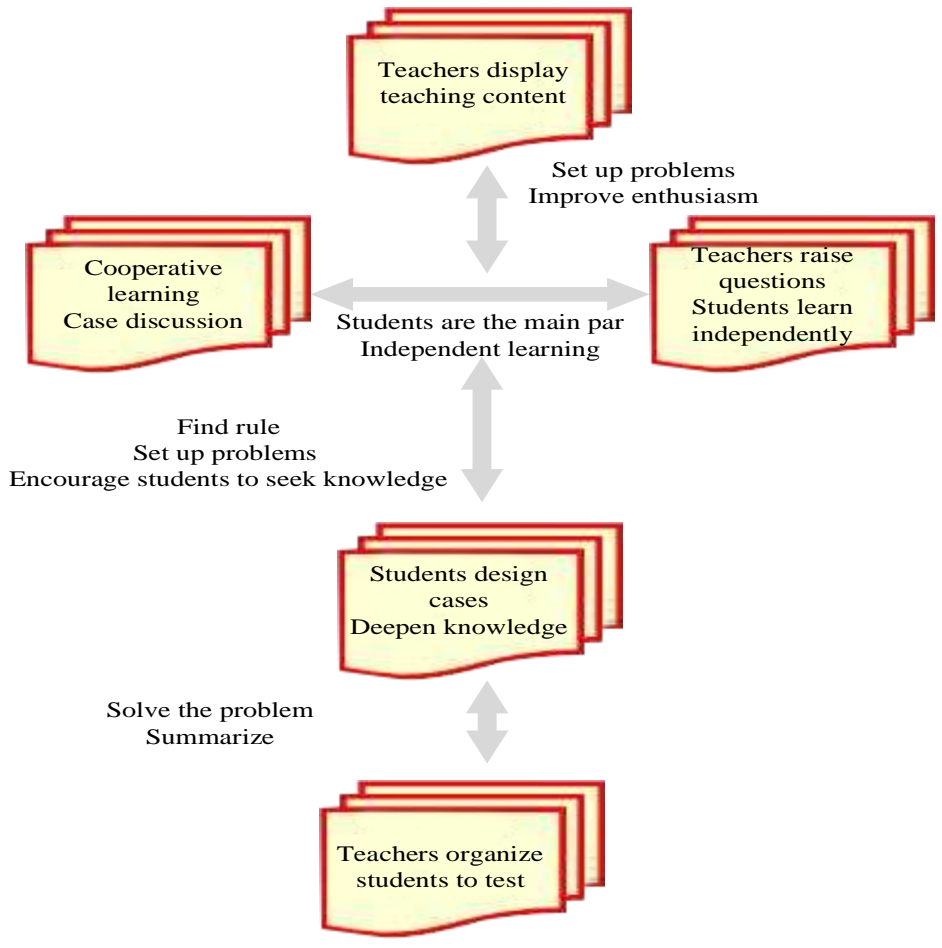

Fig. 5. The Analysis of the "Online + Offline" Teaching Procedures Based on Case Teaching Method

As can be seen from Fig. 5, teachers needed to select cases in advance, select background materials meticulously, design questions ingeniously, turn the teaching objective into questions, arouse students' interest and thirst for knowledge, and set questions that can "guide learning" according to the specific contents of cases, so that students can read and delve into the textbooks carefully, and attain the predetermined teaching objective. During the implementation, all kinds of lead-in questions were supplemented, to stimulate students' thirst for knowledge and enlighten their independent thinking. The role of teachers was "guiding" teachers, rather than "instructing" teachers, they must regard "students as the subjects", and offer service for their autonomous learning, cooperative learning and innovative learning, and create an academic atmosphere for the generation of experience knowledge. The learning forms of students can be self-study, self-inquiry, cooperation and joint research. Teachers should pay attention to leading students and letting students perceive in self-inquiry and generate questions by themselves. Shallow problems that arise from learning can be solved in self-study and self-inquiry, while problems that cannot be understood or solved should be solved by cooperation and joint research. The following combinations can be adopted: first of all, students' cooperation and joint research. For example, students were asked to have one-on-one cooperation with those around them, bring their advantages in learning and inquiry into full play, inspire and discuss with 
each other on puzzling issues. Or they can cooperate and research jointly, for example, work in a group of 4 , students sitting next to each other in the front and back rows formed a study group and learned collaboratively. Or the whole class can research jointly. Students were allowed to air their opinions and discuss on central topics or key issues. The teaching scenes are shown in Fig. 6.

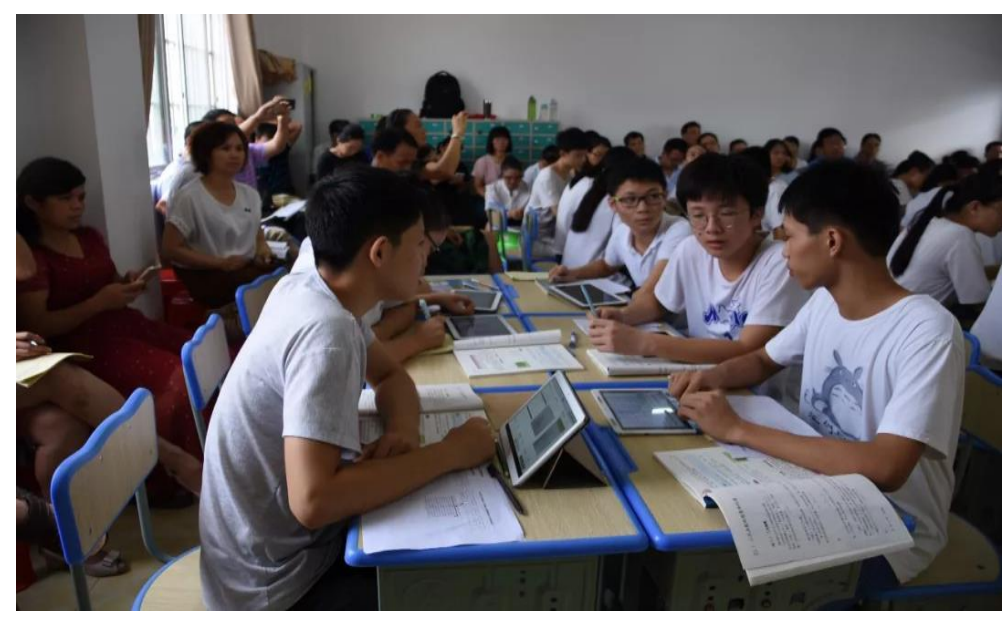

Fig. 6. Teaching Scenes of Students Discussing in Groups in "Online + Offline" Courses (http://www.sohu.com/a/249274384_99999897)

Throughout the implementation of teaching, full attention should be paid to enabling an innovative learning environment for students, so that they can make exploration and innovate learning. On the basis of self-study, self-inquiry, cooperation and joint research, students were guided to explore textbook knowledge, and rich and colorful life deeply, ask questions, search for rules and make logical reasoning, form a competitive awareness to be rat-fuck and pursue excellence, as well as divergent, convergent and reverse thinking, etc. In this step, teachers should induce queries and encourage innovation. To induce queries meant letting students analyze and think independently, suspect and repudiate existing conclusions. While to encourage innovation meant encouraging students not to be satisfied with off-the-peg methods and answers, but break the routines and dare to transcend.

In the later stage of the course, teachers should disabuse students in an artful way, according to the doubts they may have. It was needed to establish a question context, to let the teachers and students debate, present facts and evidence and make logical reasoning, etc., combined with the textbook knowledge and important hot spots in the society, and through concise explanations, wise up tips and disabusing, guide students to summarize and integrate scattered knowledge and sublime it as systematic rational knowledge, to improve students' abilities to discriminate and correct knowledge.

The testing of organizing ability was a necessary step of classroom teaching. Due to the particularity of MOOC courses, it was especially necessary to strengthen the testing, to make sure that the teaching effect was tested and fed back. To be sensible 
and practice earnestly was an important teaching goal of the entrepreneurship course, and also an ultimate value orientation of this teaching method. The teachers needed to help students build a "bridge" from theory to practice and turn what they had learned into practical actions by carrying out behavioral education.

\subsection{Teaching effect}

The research object of this paper was a class (55 students) of Grade 2018 in a given college of Jiangsu Province, China, which was taken as the teaching reform group, and another parallel class (54 students), which was taken as the control group. The two groups were taught separately. The traditional teaching mode of entrepreneurship course was employed for the control group. While giving a lesson, the teachers first reviewed the knowledge points of the last lesson by asking questions, then explained the teaching contents of this lesson, and finally summarized and arranged the content to be reviewed after class. For the teaching reform group, the "online + offline" teaching mode mentioned in this paper was adopted. The teaching effect was evaluated and analyzed in two forms:

The evaluation of students' test scores. During the experiment, a final exam was given, and two groups had a closed-book exam with the same test paper. The test scores were graded with 10 percent as an interval. The results are shown in Fig. 7.

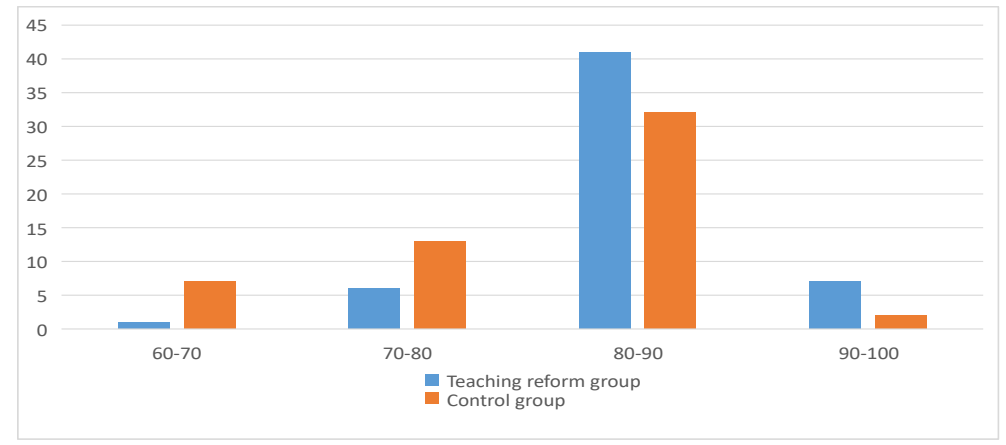

Fig. 7. Statistics of the Distribution of Test Scores

It can be seen from Fig. 7 that for the same test paper, the results and distribution of the teaching reform group was significantly better than those of the control group. 48 students in the teaching reform group scored 80-100 and accounted for $87.3 \%$, while only 34 students in the control group scored 80-100 and accounted for $63 \%$. Thus, after the teaching reform mode was implemented, the students' mastery of knowledge has been significantly enhanced and a good effect has been achieved in the understanding and application of knowledge.

The investigation on teaching effect. After the teaching was completed, a questionnaire survey was conducted on the teaching reform group. The survey content included the advantages and disadvantages of the "online + offline" entrepreneurship education courses, learning enthusiasm, autonomous learning ability, adaptability and use 
of network resources, etc., and the questionnaire was analyzed statistically. And the statistical results are shown in Tab. 5 below.

Table 5. The Evaluation of the Teaching Effect of "Online + Offline" entrepreneurship education Courses by Students in the Teaching Reform Group ( $\mathrm{N}=55)$

\begin{tabular}{|l|c|c|c|c|}
\hline \multicolumn{1}{|c|}{ The Improving Effect of This Mode } & Strongly Agree & Agree & Neutral & Disagree \\
\hline Enhance the mastery of knowledge & 43 & 12 & 0 & 0 \\
\hline Harmonize the relationship between teachers and students & 33 & 13 & 9 & 0 \\
\hline Stimulate learning interest & 35 & 12 & 8 & 0 \\
\hline It is necessary to continue with it & 42 & 7 & 6 & 0 \\
\hline
\end{tabular}

From Tab. 5 above, students were highly receptive to the "online + offline" entrepreneurship education courses, and the support rate was more than $80 \%$, which indicated that the "online + offline" teaching mode proposed in this paper was more consistent with the receptive characteristics of students. It can significantly improve their learning interest, enhance their mastery of knowledge, and advance the relationship between teachers and students in learning interaction. Students clearly expressed the wish to continue with the entrepreneurship education course through the "online + offline" teaching mode and truly improve their entrepreneurship education quality.

\section{Conclusion}

In this paper, the author explores the "online + offline" teaching reform mode of entrepreneurship education course by implementing case teaching method, in combination with an evaluation mode applicable to this course. The practice results show that "online + offline" entrepreneurship education courses combined with case teaching method can better stimulate students' learning interest, enhance their mastery of knowledge, and advance the relationship between teachers and students in learning interaction. It can truly improve students' entrepreneurship education quality, and enhance the effectiveness of entrepreneurship education course. This teaching method can satisfy the teaching demands of the entrepreneurship education course.

This study is based on existing basic theories. By clarifying the concepts, characteristics and theories of the case teaching method of entrepreneurship education course, the author innovatively integrates "online + offline" teaching modes and establishes evaluation for the teaching effect of entrepreneurship education cases based on DEMATEL-ANP. Finally, the organization and implementation steps of entrepreneurship education course are studied, by referring to the entrepreneurship education cases in colleges and universities and satisfactory teaching results are achieved. Hopefully, this study can provide a valuable reference for the development of pedagogies for quality-oriented education and entrepreneurship education. 


\section{Acknowledgement}

This work was supported by 2019 special project of entrepreneurship education work under the college philosophy and social science research in Jiangsu province (2019SJB279); 2018 teaching and research project of ideological and political theory course in vocational colleges in Jiangsu province (18JSSZZD017); 2018 special project of ideological and political work under the college philosophy and social science research in Jiangsu province (2018SJSZ238).

\section{$7 \quad$ References}

[1] Nowiński, W., Haddoud, M.Y., Lančarič, D., Egerová, D., \& Czeglédi, C. The impact of entrepreneurship education, entrepreneurial self-efficacy and gender on entrepreneurial intentions of university students in the Visegrad countries. Studies in Higher Education, 2019, vol. 44(2), pp. 361-379. https://doi.org/10.1080/03075079.2017.1365359

[2] Fretschner, M., \& Lampe, H.W. Detecting hidden sorting and alignment effects of entrepreneurship education. Journal of Small Business Management, 2019, vol. 57(4), pp. 17121737. https://doi.org/10.1111/jsbm.12448

[3] Lagrange, J.B. Teaching mathematics online: emergent technologies and methodologies. Research in Mathematics Education, 2014, vol. 16(2), pp. 208-212. https://doi.org/10.10 $\underline{\text { 80/14794802.2014.918342 }}$

[4] Zhang, P.X., Zhang, J.B., Ou, Q., Lv, S.C. Establishment and implementation of online and offline teaching mode in the course of Biochemistry. Chinese Journal of Clinicians(Electronic Edition), 2016, vol. 10(24), pp. 3853-3856.

[5] Hedderich, R.B.N. Virtual connections: online activities and projects for networking language learnersby mark warschauer. Die Unterrichtspraxis / Teaching German, 1997, vol. 30(1), pp. 105-107. https://doi.org/10.2307/3531234

[6] Li, M.L., \& Ren, Y.J. A multimedia teaching model for "sports statistics" based on ARCS motivation theory. International Journal of Emerging Technologies in Learning, 2018, vol. 13(9), pp. 15-28. https://doi.org/10.3991/ijet.v13i09.8972

[7] Bayona, J.A., \& Castañeda, D.I. Influence of personality and motivation on case method teaching. The International Journal of Management Education, 2017, vol. 15(3), pp. 409428. https://doi.org/10.1016/j.ijme.2017.07.002

[8] Çakmak, Z., \& Akgün, İ.H. A Theoretical Perspective on the Case Study Method. Journal of Education and Learning, 2018, vol. 7(1), pp. 96-102.

[9] Mcwhirter, N.D., \& Shealy, T. Teaching decision-making for sustainable infrastructure: a wind energy case study module. International Journal of Sustainability in Higher Education, 2018, vol. 19(3), pp. 893-911. https://doi.org/10.1108/ijshe-10-2017-0183

[10] Chen, Y. "Trinity" entrepreneurship education model reform -- Based on the practical experience of Zhejiang Province's Undergraduate Colleges. Continue Education Research, 2013, vol. 23(12), pp. 108-110.

[11] Zhu, L. Construct a Model of "Double In. \& Quartet Drives" to Promote the Reform of Innovation and Entrepreneurship Education: Application and Exploration by Shandong Agricultural University. China Agricultural Education, 2016, vol. 26(6), pp. 1-10.

[12] Wei, Y.D. Wu, T.J. Research of Innovation and Entrepreneurship Education into Professional Education. Journal of Shenyang Institute of Engineering, 2019, vol. 15(4), pp. 532535 . 
Paper — "Online + Offline" Course Teaching Based on Case Teaching Method: A Case Study...

[13] Gu, X.J. On the application of case teaching method in high school entrepreneurship teaching. China Extracurricular Education. 2017, vol.18(12), pp. 47-48.

[14] Clegg, B., Wang, T., \& Ji, P. Understanding customer needs through quantitative analysis of Kano's model. International Journal of Quality \& Reliability Management. 2010, vol. 27(2) pp. 173-184. https://doi.org/10.1108/02656711011014294

\section{Authors}

Shuyang Hua is an associate professor in the Wuxi Institute of Technology, Wuxi, China (15961834524@139.com).

Xiaojun Jiang is a lecturer in the Wuxi Institute of Technology, Wuxi, China (15961834524@139.com).

Article submitted 2020-02-03. Resubmitted 2020-03-03. Final acceptance 2020-03-04. Final version published as submitted by the authors. 